\title{
Modulatory factors in the effect of energy density on energy intake
}

\author{
M. S. Westerterp-Plantenga* \\ Department of Human Biology, Maastricht University, P. O. Box 616, 6200 MD, Maastricht, The Netherlands
}

The effect of energy density (ED) on energy intake (EI) has been assessed in short-term and long-term experiments. In the short term, it was found that ED affects EI directly in situations when the subjects cannot estimate the ED of the food; then subjects mainly monitor the weight of the food ingested. In the long term, the effects of ED on EI are modulated. Average daily EI appears to be related to ED of the food and drinks when ED is determined by specific macronutrients, but not when ED is only determined by the weight of water. Thus, the short-term effect ED has on EI cannot be extrapolated to the long term, because a possible dominating effect of the weight of water determining ED undoes the relationship of ED with EI. Moreover, in the long-term portion sizes are used to compensate for correctly estimated ED, resulting in less variation in EI than ED alone would imply. Finally, dietary restraint compensates for the effect of a relatively high ED on daily EI, whereas dietary unrestraint compensates for the effect of relatively low ED on daily EI. We conclude that the short-term effect of $\mathrm{ED}$ on $\mathrm{EI}$ is modulated by the effect of water on ED, and compensated for by the effect of dietary restraint and adapted portion sizes.

Macronutrient composition: Dietary restraint: Obesity: Energy density: Portion size: Universal eating monitor

With regard to the role of energy density (ED) in energy intake (EI) regulation, the question is whether and how average daily EI is related to the ED of food and drinks consumed (Spiegel, 1973; Westerterp-Plantenga et al. 1990, 1996a,b; Stubbs et al. 1995, 1998; Poppit \& Prentice, 1996; Rolls \& Bell, 1999; Westerterp-Plantenga, 2000, 2001), in the short term as well as in the long term. ED is defined as follows:

$\mathrm{ED}=\frac{\text { carbohydrate }(\mathrm{kJ})+\operatorname{protein}(\mathrm{kJ})+\mathrm{fat}(\mathrm{kJ})+\text { alcohol }(\mathrm{kJ})}{\text { carbohydrate }(\mathrm{g})+\operatorname{protein}(\mathrm{g})+\text { fat }(\mathrm{g})+\text { alcohol }(\mathrm{g})+\text { water }(\mathrm{g})+\text { undigestibleparts }(\mathrm{g})}$

ED represents metabolizable energy $(\mathrm{kJ})$ /gross weight $(\mathrm{g})$, since the Atwater factors are defined in this way; it does not represent energy/volume. If volume is used, then one would have to take the specific gravity of the food into account. For instance, when air is added, as in a soufflé (Rolls \& Bell, 1999), this might have only a very short-term volume effect.

\section{Short-term effects of energy density on energy intake}

Food intake during a meal was studied using cumulative food intake curves from a universal eating monitor (e.g. Westerterp-Plantenga et al. 1990, 2000; WesterterpPlantenga \& Verwegen, 1999). The ED of an otherwise familiar meal was covertly changed from 4.8 to 6.1 or $4.0 \mathrm{~kJ} / \mathrm{g}$. This resulted in a change in macronutrient composition from 15:15:30 (\% energy as carbohydrate, protein and fat respectively) to: (1) 50:10:40 (high fat); (2) 70:10:20 (high carbohydrate); (3) 50:30:20 (high protein) (Westerterp-Plantenga et al. 1990). Decrease of ED to $4.0 \mathrm{~kJ} / \mathrm{g}$ was reached by adding $20 \mathrm{~g}$ fibre (guar gum) to the meals with the basic macronutrient composition $(55: 15: 30)$.
The covert changes in ED of an otherwise familiar meal did not cause changes in the cumulative intake curve variables (Westerterp-Plantenga et al. 1990). In addition, the shape of the individual cumulative food intake and satiation curves showed very little variability despite experimentally energy-enriched meals (Fig. 1(A and B); Westerterp-Plantenga et al. 1990, 2000). Similar results on subjects monitoring weight of food rather than energy of food during a meal were reported by Rolls \& Bell, (1999).

However, we showed that after the energy-enriched lunch-meals, as well as after the meals energy-diluted by fibre, subjects had a longer inter-meal interval (6.5 (SD $0.5)$ v. $5.5(\mathrm{SD} 0.4) \mathrm{h}$ ), and a lower EI during dinner (2.9 (SD 0.2) MJ v. $3.4(\mathrm{SD} 0 \cdot 2$ ) MJ) (Westerterp-Plantenga et al. 1996a, 2000).

\section{Analysis of energy-density effects on average daily energy intake}

From the effect of ED on EI during a meal, the question remains as to how ED affects average daily EI. Any dataset that contains fully reliable measurements of the components contributing to ED can be used to analyse the determinants of ED and the relationship between EI and ED. This was, for instance, executed in three datasets (Westerterp-Plantenga, 2001).

The relative quantitative contributions of the determinants of ED and of EI in the three datasets were analysed using a simple regression analysis. Table 1 gives total EI and energy from carbohydrate, protein and fat $(\mathrm{kJ})$. Moreover, it gives weight of fat, carbohydrate, protein and

\footnotetext{
Abbreviations: ED, energy density; EI, energy intake.

* Corresponding author: Dr Margriet S. Westerterp-Plantenga, fax +31 43 3670976, email m.Westerterp@hb.unimass.nl
} 


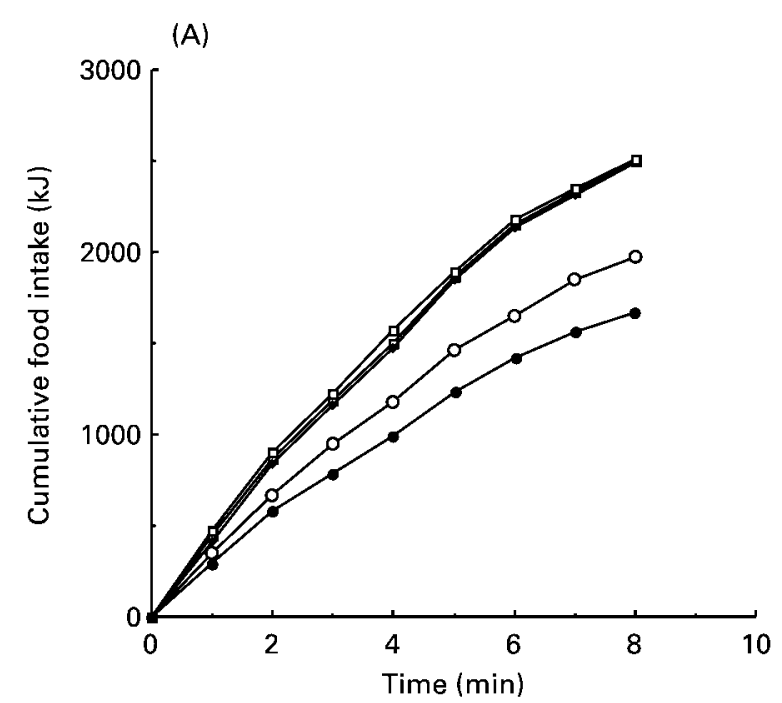

(B)

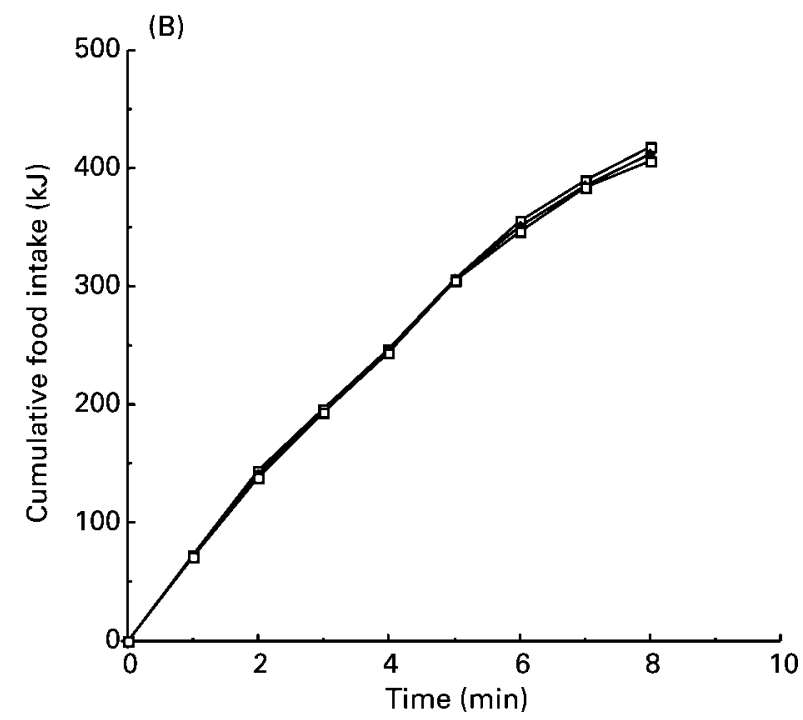

Fig. 1. Example of cumulative food intake over time $((A), k J)$ and in $((B), g)$ of five similar meals only differing in energy density (ED) and macronutrient composition. Subjects were normal-weight women. $\square$, ED $6.1 \mathrm{~kJ} / \mathrm{g}$, high carbohydrate; $\bullet$, ED $6.1 \mathrm{~kJ} / \mathrm{g}$, high protein; 口, ED $6.1 \mathrm{~kJ} / \mathrm{g}$, high fat; O, ED $4.8 \mathrm{~kJ} / \mathrm{g} ; \bullet$, ED $4.0 \mathrm{~kJ} / \mathrm{g} . \%$ Energy from carbohydrate, protein and fat respectively were: highcarbohydrate 70:10:20; high-protein 50:30:20; high-fat 50:10:40. (From Westerterp-Plantenga, 1990a.)

water. It also shows ED and macronutrient composition (\% energy) of the three datasets that were analysed. Table 2 gives the simple regression analysis for each of these three datasets, which shows the relative contribution of carbohydrate, protein and fat $(\mathrm{kJ})$ and carbohydrate, protein, fat and water ( $\mathrm{g}$ ) to ED and to EI.

The relationship of EI to ED in each dataset was as follows: dataset 1 (dietitians) $r 0.38, P=0.0001$; dataset 2 (women) $r 0.93, P=0.0001$; dataset 3 (men) $r 0 \cdot 17, P=0.27$.

From the simple regression analyses it appears that variation in ED was determined positively by the variation in energy from fat and carbohydrate, and inversely by the variation in the weight from water, fat and carbohydrate (Table 2). The variation in the relative proportion of protein was so small that it did not contribute much to the variation in ED.

From the differences between the outcomes of the three datasets it appears that ED is related to EI when ED is related to the energy content and the weight of macronutrients (datasets 1 and 2), and possibly, but not necessarily, to the weight of water (dataset 1). When water is the dominant component determining ED, EI is not related to ED (dataset 3). In other words, when the variation in ED is only determined by the weight of water, ED does not play a role in EI regulation. This means that EI becomes independent of ED when only the range in the weight of water determines the range in ED.

When EI was also determined by the weight of water, the weight of water correlated positively with EI, whereas it correlated negatively with ED. This concerns the weight of water in the food, which is inclusive in food intake. It means that the EI from the food cannot take place without the accompanying water. When water is part of the food, it affects stomach emptying, and thus satiety (Himaya \& Louis-Sylvestre, 1998).

Because the determinants of ED play different roles in EI, we cannot simply substitute the effects of macronutrients on EI regulation by the effect of ED. This means that the characteristics of the macronutrients still play an important role in EI, and that ED can be considered as one of those. The main effect ED has on EI comes from the effect of fat on ED, and subsequently on EI, as shown in datasets 1 and 2 .

In conclusion, average daily EI is related to ED of the food and drinks when ED is determined by specific macronutrients. When ED is only determined by the weight of water, it is not related to EI (Westerterp-Plantenga, 2001). The difference between the effect of ED on EI in the short term or in the long term lies in the role of water. When variation in ED is only determined by variation in water intake, it has no effect on EI anymore. This also implies that the variation in ED of the food is more important than the variation in ED of drinks, as far as EI is considered. Thus, water is a modulating factor in the effect of ED on EI in the long term.

\section{Food choice adjustment to energy-density categories}

To assess the effect of ED of foods in daily food choice and portion size (as determined by the subject), we examined EI in relation to ED of foods in obese and non-obese women (Westerterp-Plantenga et al. 1996a).

From sixty-eight subjects (thirty-four obese and thirtyfour non-obese women, matched for age (20-50 years) controlled food intake diaries of two weekdays and one weekend day were analysed.

The obese women had a food intake distribution over three classes of ED of foods, i.e. $0 \cdot 0-7 \cdot 5,7 \cdot 5-15 \cdot 0$ and $15 \cdot 0-22.5 \mathrm{~kJ} / \mathrm{g}$ of 24,52 and $24 \%$ energy respectively, with a macronutrient composition of 39:17:44 (\% energy as carbohydrate, protein and fat respectively). In the nonobese women the food intake distribution over these three classes was 38, 49 and $13 \%$ energy, with a macronutrient composition of 46:17:37 (\% energy as carbohydrate, protein and fat respectively). The distribution in the 
Table 1. Energy intake $(E I)$ from carbohydrate $(C)$, protein $(P)$ and fat $(F)$, weight of $F, C$ and $P^{\prime}$ and water $(W)(g)$, energy density (ED) and macronutrient composition (\% energy) in three datasets

\begin{tabular}{|c|c|c|c|c|c|c|}
\hline \multirow{3}{*}{$\begin{array}{l}\text { Dataset... } \\
\text { Subjects... }\end{array}$} & \multicolumn{2}{|c|}{$1^{*}$} & \multicolumn{2}{|c|}{$2 \dagger$} & \multicolumn{2}{|c|}{$3+$} \\
\hline & \multicolumn{2}{|c|}{ Dietitians ( $n$ 16) } & \multicolumn{2}{|c|}{$\begin{array}{l}\text { Women in respiration } \\
\text { chamber }(n 8)\end{array}$} & \multicolumn{2}{|c|}{$\begin{array}{l}\text { Men in respiration } \\
\text { chamber }(n 8)\end{array}$} \\
\hline & Mean & SD & Mean & SD & Mean & SD \\
\hline $\mathrm{El}(\mathrm{MJ})$ & 9.4 & $2 \cdot 3$ & $9 \cdot 7$ & 1.0 & 14.5 & 3.4 \\
\hline $\mathrm{C}(\mathrm{MJ})$ & 4.6 & 1.2 & 5.4 & 0.6 & 7.0 & 1.8 \\
\hline $\mathrm{P}(\mathrm{MJ})$ & 1.3 & $0 . \overline{3}$ & 1.4 & 0.1 & $2 \cdot 2$ & 0.5 \\
\hline$F(M J)$ & 2.9 & 0.9 & $2 \cdot 9$ & 0.4 & $5 \cdot 3$ & 1.2 \\
\hline$C(\mathrm{~g})$ & 288 & 77 & 338 & 36 & 438 & 115 \\
\hline$P(g)$ & 81 & 17 & 88 & 7 & 138 & 31 \\
\hline$F(g)$ & 78 & 25 & 78 & 11 & 143 & 32 \\
\hline W (g) & 2665 & 934 & 2903 & 97 & 2735 & 1478 \\
\hline $\mathrm{ED}(\mathrm{kJ} / \mathrm{g})$ & 3.2 & 0.8 & $2 \cdot 8$ & 0.3 & 4.7 & 1.7 \\
\hline $\mathrm{C}: \mathrm{P}: \mathrm{F}$ (\% energy) & \multicolumn{2}{|c|}{$49: 14: 31 \S$} & \multicolumn{2}{|c|}{$56: 14: 30$} & \multicolumn{2}{|c|}{ 48:15:37 } \\
\hline
\end{tabular}

* Dataset 1 was obtained from a controlled free-living experiment with dietitians, who recorded their food intakes for 1 week without under-reporting (Goris \& Westererp, 2000).

†Datasets 2 and 3 were from respiration chamber experiments with ad libitum food consumption (Westerterp-Plantenga, 2001).

$\S 6 \%$ Energy from alcohol.

obese women was significantly different from the values of the non-obese and from the Dutch food guideline values (Westerterp-Plantenga et al. 1996a). With regard to portion sizes it appeared that the obese women took larger portions of food with a high ED than the

Table 2. The relative contribution ( $r)$, obtained by simple regression analysis, of carbohydrate $(C)$, protein $(P)$, and fat $(F),(k J)$, weight of $C, P, F$ and water $(W)(g)$ to energy intake $(E I)$ and energy density (ED) in three datasets $\dagger$

(Correlation coefficients)

\begin{tabular}{|c|c|c|c|}
\hline Dataset§ & & El & ED \\
\hline \multirow[t]{7}{*}{ 1. Dietitians $n 16 \ddagger$} & $C(\mathrm{~kJ})$ & $0 \cdot 81^{\star * \star}$ & $0.28^{\star *}$ \\
\hline & $P(k J)$ & $0.62^{* \star *}$ & 0.16 \\
\hline & $\mathrm{F}(\mathrm{kJ})$ & $0 \cdot 81^{* \star *}$ & $0.47^{\star \star *}$ \\
\hline & $C(g)$ & $0 \cdot 81^{\star \star \star}$ & $0.28^{\star *}$ \\
\hline & $P(g)$ & $0.62^{\star \star \star}$ & $0 \cdot 16$ \\
\hline & $F(g)$ & $0 \cdot 81^{\star * \star}$ & $0.47^{\star \star *}$ \\
\hline & $W(g)$ & $0.33^{\star \star \star}$ & $0.64^{\star \star \star}$ \\
\hline \multirow{7}{*}{$\begin{array}{l}\text { 2. Females, } n 8 \text { in } \\
\text { respiration-chamber }\end{array}$} & $\mathrm{C}(\mathrm{kJ})$ & $0.54^{*}$ & 0.50 \\
\hline & $P(k J)$ & 0.46 & 0.41 \\
\hline & $\mathrm{F}(\mathrm{kJ})$ & $0.77^{\star \star \star}$ & $0.85^{\star \star *}$ \\
\hline & $C(g)$ & $0.54^{*}$ & 0.50 \\
\hline & $P(g)$ & 0.46 & 0.41 \\
\hline & $F(g)$ & $0 \cdot 77^{\star \star \star}$ & $0.85^{\star \star *}$ \\
\hline & $W(g)$ & 0.21 & 0.15 \\
\hline \multirow[t]{7}{*}{ 3. Males, $n 8$ in respiration chamber } & $\mathrm{C}(\mathrm{kJ})$ & $0 \cdot 89^{\star \star \star}$ & 0.23 \\
\hline & $P(k J)$ & $0.98^{* * *}$ & 0.22 \\
\hline & $\mathrm{F}(\mathrm{kJ})$ & $0.97^{\star \star \star}$ & 0.27 \\
\hline & $C(g)$ & $0 \cdot 89^{\star \star \star}$ & 0.23 \\
\hline & $P(g)$ & $0.98^{\star \star \star}$ & 0.22 \\
\hline & $\mathrm{F}(\mathrm{g})$ & $0.97^{\star * \star}$ & 0.27 \\
\hline & $W(g)$ & $0 \cdot 66^{\star \star \star}$ & $0.77^{\star * *}$ \\
\hline
\end{tabular}

${ }^{\star} P<0.05,{ }^{* \star} P<0.01,{ }^{\star * *} P<0.001$

† All relationships were positive, except for $W(\mathrm{~g})$. W (g) was negatively related to ED (datasets 1 and 3 ), but positively to El (datasets 1 and 3 ).

‡Dataset 1 was obtained from a controlled free-living experiment with dietitians, who recorded their food intakes for 1 week without under-reporting (Goris \& Westerterp, 2000).

$\S$ Datasets 2 and 3 were from respiration chamber experiments with ad libitum food consumption (Westerterp-Plantenga, 2001). non-obese did, and also larger than standard sizes would suggest. They took smaller portions of food with a low $\mathrm{ED}$ in comparison with the non-obese subjects and in comparison with the standard sizes. In the non-obese, portion sizes were almost standard portion sizes (WesterterpPlantenga et al. 1996a). With regard to the variation of portion sizes in relation to ED of the food, Green et al. (1994) also reported that portion size was inversely related to ED of snacks of $7 \cdot 6-16.5 \mathrm{~kJ} / \mathrm{g}$ in healthy nonobese males.

Thus, in daily life, portion size appears to be a learned or culturally determined modulatory factor compensating for a straightforward effect of ED on EI (WesterterpPlantenga, 2001).

\section{Modulating long-term effects of energy density on energy intake}

Of all the macronutrients, the exceptionally high ED of fat affects the effect of ED on EI most of all through 'passive' (over)consumption. However, a long-term change in \% energy from fat causing a change in ED and subsequently in EI and body weight appeared to be possibly compensated for by dietary restraint (Westerterp-Plantenga et al. 1998). In a multi-centre study, the MSFat study, carried out in the Netherlands, subjects received a high-fat $v$. reduced-fat diet for 6 months from a laboratory supermarket. All the foods the subjects took from the shop were recorded and the leftovers were also recorded. The analyses in relation to dietary restraint showed the following. A reduced-fat diet for 6 months in combination with unrestrained eating behaviour, which resulted in positive EI compensation, contributed to weight maintenance. Weight reduction was the consequence of a reduced-fat diet in combination with restrained eating behaviour, which did not compensate for the reduced EI. A high-fat diet combined with unrestrained eating behaviour led to increased EI and body weight. Restrained eating behaviour 
(A)

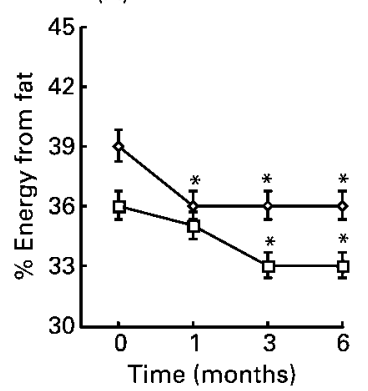

(C)

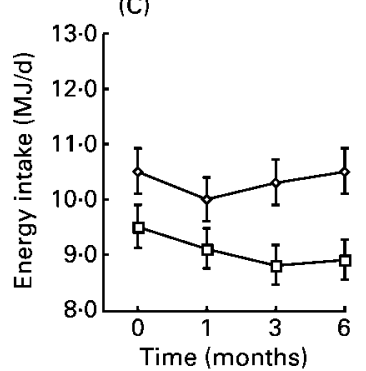

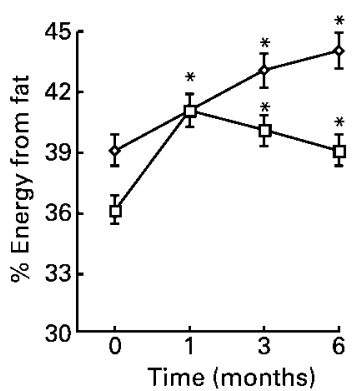

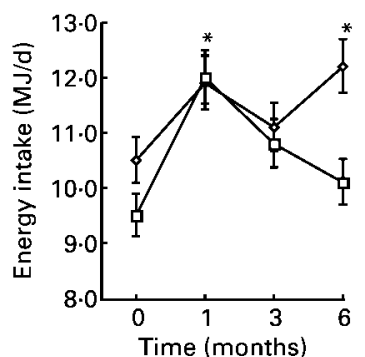

(B)
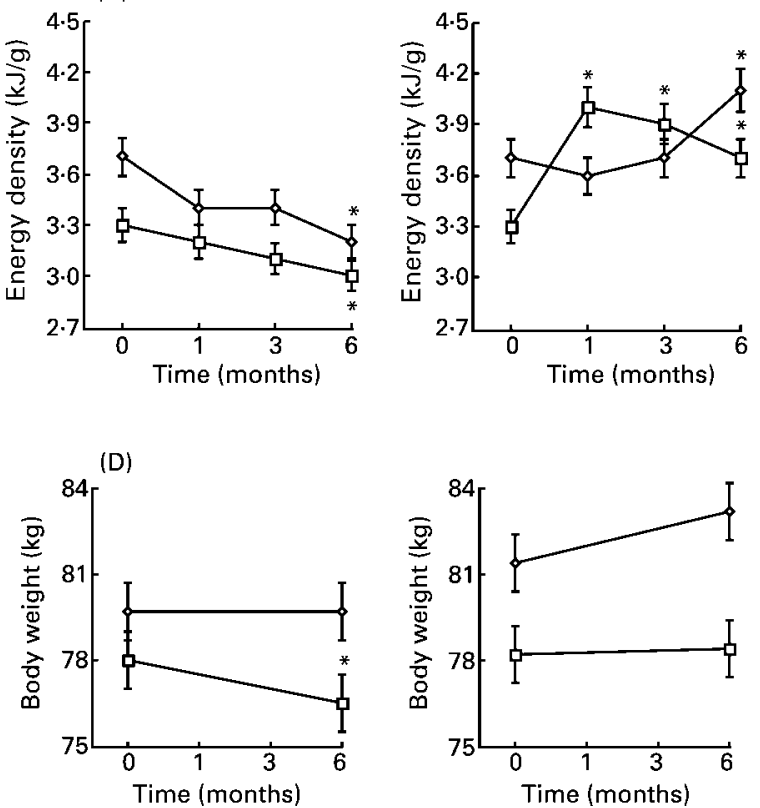

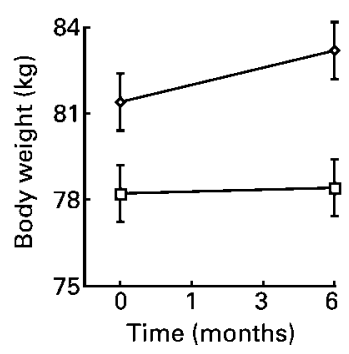

Fig. 2. Percentage energy from fat (A), energy density (B), average daily energy intake (C) and body weight (D) during a 6-month trial in dietary restrained $(\square)$ and unrestrained $(\diamond)$ men and women. The subjects were kept on a reduced-fat (left-hand pane) or high-fat (right-hand pane) diet. (From Westerterp-Plantenga et al. 1998.)

with a high-fat diet prevented such an increase in EI and body weight. Thus, dietary restraint compensated for an increase in ED, whereas lack of dietary restraint compensated for a decrease in ED (Fig. 2(A, B, C and D); Westerterp-Plantenga et al. 1998).

Therefore, dietary restraint (which may use adapted portion size) can be considered as a modulatory factor in the effect of ED on EI in the long term.

\section{Conclusions}

From the straightforward effect ED has on EI during a meal, we conclude that subjects monitor the weight of food ingested in the short term. However, this cannot be extrapolated to the long term, because then a possible dominating effect of the weight of water determining ED undoes the relationship of ED with EI. Second, in the long term, portion sizes are used to compensate for correctly estimated $\mathrm{ED}$, resulting in less variation in EI than ED alone would imply. Third, in the long term, dietary restraint appears to compensate for the effect of a relatively high ED on EI, whereas dietary unrestraint compensates for the effect of relatively low ED on EI.

For the effect of ED on average daily EI in the long term, we conclude that the short-term effect is modulated by the effect of water on ED, and compensated for by the effect of dietary restraint and adapted portion sizes.

\section{References}

Goris AHC \& Westerterp KR (2000) Under-reporting of habitual food intake: can it be improved? $\mathrm{Br} J$ Nutr $\mathbf{8 3}$, 363-369.
Green SM, Burley VJ \& Blundell J (1994) Effect of fat- and sucrose-containing foods on the size of eating episodes and energy intake in lean males: potential for causing overconsumption. Eur J Clin Nutr 48, 547-555.

Himaya A \& Louis-Sylvestre J (1998) The effect of soup on satiation. Appetite 30, 199-210.

Poppit \& Prentice (1996) Energy density and its role in the control of food intake: evidence from metabolic and community studies. Appetite 26, 153-174.

Rolls BJ \& Bell EA (1999) Intake of fat and carbohydrate: role of energy density. Eur J Clin Nutr 53, S166-S173.

Spiegel TA (1973) Caloric regulation of food intake in man. J Comp Physiol Psychol 84, 24-37.

Stubbs RJ, Johnstone AM, O'Reilly LM, Barton K \& Reid C (1998) The effect of covertly manipulating the energy density of mixed diets on ad libitum food intake in 'pseudo free-living' humans. Int $J$ Obes Relat Metab Disord 22, 980-987.

Stubbs RJ, Ritz P, Coward WA \& Prentice AM (1995) Covert manipulation of the ratio of dietary fat to carbohydrate and energy density: effect on food intake and energy balance in free living men eating ad libitum. Am J Clin Nutr 62, 330-337.

Westerterp-Plantenga MS (2000) Eating behaviour in humans, characterized by cumulative food intake curves - a review. Neurosci Biobehav Rev 24, 239-248.

Westerterp-Plantenga MS (2001) Analysis of energy density of food in relation to energy intake regulation in human subjects. Br J Nutr 85, 351-361.

Westerterp-Plantenga MS, Pasman WJ, Yedema MJW \& Wijckmans-Duijsens NEG (1996a) Energy intake adaptation of food to extreme energy densities of food by obese and non-obese women. Eur J Clin Nutr 50, 401-407.

Westerterp-Plantenga MS, van de Ven M, Wouters L \& Saris WHM (1996b) Satiation and satiety related to eating rate and meal characteristics in obese and non-obese restrained and 
unrestrained eating women. Int $J$ Obes Relat Metab Disord 20, 105.

Westerterp-Plantenga MS \& Verwegen CRT (1999) The appetizing effect of an aperitif in overweight and normal weight humans. Am J Clin Nutr 69, 205-212.

Westerterp-Plantenga MS, Westerterp KR, Nicolson NA, Mordant A, Schoffelen PFM \& ten Hoor F (1990) The shape of the cumulative food intake curve in humans, during basic and manipulated meals. Physiol Behav 47, 569-576.

Westerterp-Plantenga MS, Wijckmans-Duijsens NEG, Verboeketvan de Venne WPG, de Graaf K, van het Hof KH \& Westrate JA (1998) Energy intake and body weight effects of six months reduced or full fat diets, as a function of dietary restraint. Int $J$ Obes Metab Disord 22, 14-22. 